\title{
Fditorial
}

\section{Real-time polymerase chain reaction for detecting SARS-COV-2 in Indonesia: are the results reliable?}

\author{
Monica Dwi Hartanti* \\ Department of Medical Biology, Faculty of Medicine, Trisakti University
}

Since it was first reported in Wuhan, China, in December 2019, coronavirus disease 2019 (COVID-19) has been considered as a pandemic. ${ }^{(1)}$ It is caused by severe acute respiratory syndrome coronavirus 2 (SARSCoV-2), a member of the Coronavirus family. ${ }^{(1)}$ In Indonesia, this disease was first detected in the beginning of March 2020 and has been spreading in 34 provinces and more than 417 districts all over Indonesia, with more than 27,000 confirmed cases and a case fatality rate of around $6 \%{ }^{(2-3)}$ The Indonesian Government has implemented several strategies in order to slow down the spread of COVID-19, such as promoting social distancing, implementing largescale social restriction, providing personal protection equipment for health workers, adding hospitals for treating COVID-19 patients, and improving diagnostic management. Currently the most widely used method of confirming COVID19 cases is real-time PCR.

The term "polymerase chain reaction" was first introduced in 1985 in a paper written by Saiki et al. ${ }^{(4)}$ The general concept of PCR involves primers, DNA polymerase, nucleotides, ions, and DNA template and consists of cycles that comprise 3 steps, which are DNA denaturation, primer annealing, and extension. PCR has indeed provided a significant contribution to the development of biomedical research. However, the most fundamental change in PCR application was the introduction of the concept of real-time PCR.
Real-time PCR or quantitative PCR (qPCR) is a method of quantifying the amplified nucleic acid present in a sample in real time using a fluorescent dye or fluorescent-labeled oligos. The fluorescence will be measured after each cycle and the fluorescent signal intensity denotes the amount of transient DNA amplicons in a sample at that particular time. The intensity of the fluorescent signal will be below the detectable level at the beginning of cycles due to background signals. Once it increases above the level, the intensity corresponds proportionally to the preliminary number of DNA molecules in the sample. This is the point where the absolute quantity of target DNA in the sample is measured based on a calibration curve created by serial diluted standard samples with known concentrations. This point is known as the quantification cycle $(\mathrm{Cq})$ or the cycle threshold $(\mathrm{Ct})$.

The quantitative real-time PCR is known to play a critical role in detecting and quantifying viral pathogens due to its appropriate sensitivity and specificity, as well as fast and highthroughput results compared to other methods, such as ELISA and culture methods. ${ }^{(5)}$ Additionally, cross-contamination can be avoided because qPCR does not require further sample manipulation after the amplification. Furthermore, its ability to amplify several targets in a single reaction makes that users can include internal amplification controls in one run. The multiplexing option is essential for detection and 
quantification in diagnostic qPCR assays that rely on the inclusion of internal amplification controls.

According to the World Health Organization (WHO), one-step quantitative realtime PCR (qRT-PCR) assays have become a standard assessment for identifying SARS-CoV2 in suspected patients. ${ }^{(6)}$ COVID-19 cases are confirmed by detecting unique sequences of viral RNA by nucleic acid amplification tests such as qRT-PCR. The targeted viral genes so far include the three genes that encode structural proteins; N (nucleocapsid), E (envelope), and S (spike), as well as the RNA-dependent RNA polymerase (RdRp) gene that plays critical roles in viral RNA synthesis. RNA extraction should be done in a biosafety cabinet.

It seems that qRT-PCR is the most widely used and preferred method for confirming COVID-19 cases. The only critical problem regarding the real-time PCR test would be any possibility of false negative or false positive results. It has been reported that a patient in Wuhan, China, had three negative SARS-CoV2 RT-PCR testing results within 3 weeks before showing positive results for both RT-qPCR and next generation sequencing (NGS) testing from bronchoalveolar lavage fluid (BALF) samples. ${ }^{(7)}$ Another study in Wuhan reported that 21 of 70 hospitalized COVID-19 patients with two consecutive negative results had positive results for the third testing. ${ }^{(8)}$ What would be causing these false negative results?

There are several factors that are thought to be related to the inconsistency of qPCR results. Firstly, the primers. Those used in qRT-PCR can be influenced by the variant of viral RNA sequences, leading to the discrepancy of the results. There are 3 strains of SARS-CoV-2 that have been identified, type A, B, and C ${ }^{(9)}$ A recent study shows that the strain of SARS-CoV-2 in Indonesia is different from those three strains, with mutation sites in the $\mathrm{S}$ protein and open reading frame $(\mathrm{ORF})$ protein. ${ }^{(10)}$ Primers that are able to detect the Indonesian SARS-CoV-2 strains are needed to produce accurate and consistent results.

Secondly, the laboratory practice standards and personnel skills. qRT-PCR is a method that requires skills in the relevant technical procedures, such as pipetting skills. Additionally, safety procedures must be implemented in running this method in at least a biosafety level 2 laboratory. There are 148 laboratories across Indonesia that have been certified to perform this test and more than 200,000 samples have been tested so far (as of 2 June 2020). ${ }^{(2)}$

Lastly, sampling procedures, such as sample types, collecting timing and tools, and sampling transfer. The sample should be collected from the upper (nasopharyngeal and oropharyngeal swab) and/or lower respiratory tracts (sputum and/or endotracheal aspirate or bronchoalveolar lavage). ${ }^{(11)}$ The collection time must be carefully determined due to different viral load kinetics of SARS-CoV-2 in different patients, leading to different results. ${ }^{(7)}$ Dacron or polyester flocked swabs should be used for collecting samples and the latter must be transferred to the laboratory at $2-8^{\circ} \mathrm{C}$ as soon as possible after collection to prevent interference by inhibitors in the sample. ${ }^{(11)}$

Indonesia has been able to identify more than 27,000 SARS-CoV-2 positive samples from 237,947 total samples (as of 2 June 2020) using qRT-PCR methods (equal to 0.03 test per thousand inhabitants) and the recovery numbers have been increased to almost 8,000 cases. ${ }^{(2,3)}$ Thus, the results of qRT-PCR have been used to confirm many suspected COVID-19 cases in Indonesia. However, the interpretation of the results must be made cautiously. Negative results with clinical characteristics of COVID19 must be followed by multiple sample types at various points of time. It is worth noting that the combination of qRT-PCR results and clinical features should always be considered in managing the disease. Good laboratory practice standards must be implemented in testing samples of COVID-19 cases to improve the resulting quality and reduce the inconsistency. 


\section{REFERENCES}

1. World Health Organization. COVID 19 public health emergency of international concern (PHEIC). Geneva: World Health Organization; 2020.

2. Corona Disease Mitigation Acceleration Task Force. COVID-19 in Indonesia (2 June 2020). Jakarta: Corona Disease Mitigation Acceleration Task Force; 2020.

3. Hasell J, Ortiz-Ospina E, Mathieu E, et al. Coronavirus (COVID-19) testing. Our World in Data;2020.

4. Saiki RK, Scharf S, Faloona F, et al. Enzymatic amplification of beta-globin genomic sequences and restriction site analysis for diagnosis of sickle cell anemia. Science 1985;230:1350-4. doi: 10.1126/ science. 2999980.

5. Shen M, Zhou Y, Ye J, et al. Recent advances and perspectives of nucleic acid detection for coronavirus. J Pharm Anal 2020;10:97-101. https:/ /doi.org/10.1016/j.jpha.2020.02.010.

6. World Health Organization. Laboratory testing for coronavirus disease 2019 (COVID-19) in suspected human cases: interim guidance. Geneva: World Health Organization;2020.
7. Wang Y, Kang H, Liu X, Tong Z. Combination of RT-qPCR testing and clinical features for diagnosis of COVID-19 facilitates management of SARS-CoV-2 outbreak. J Med Virol 2020;1-2. doi: 10.1002/jmv.25721.

8. Xiao AT, Tong YX, Gao C, et al. Dynamic profile of RT-PCR findings from 301 COVID-19 patients in Wuhan, China: a descriptive study. J Clin Virol 2020;104346.https://doi.org/10.1016/j.jcv.2020. 104346.

9. Forster P, Forster L, Renfrew C, Forster M. Phylogenetic network analysis of SARS-CoV-2 genomes. Proc Natl Acad Sci USA 2020; 117:92413. doi: 10.1073/pnas.2004999117.

10. Global Initiative on Sharing All Influenza Data. Genomic epidemiology of hCoV-19. Bonn: Global Initiative on Sharing All Influenza Data (GISAID), 2020.

11. Pengurus Pusat Perhimpunan Dokter Spesialis Patologi Klinik dan Kedokteran Laboratorium Indonesia. Manajemen spesimen dan diagnosis laboratorium kasus suspek 2019-nCoV;2020. 